\title{
Photocatalytic Degradation of Algae and its By-product using Rotating Photocatalytic Oxidation Disk Reactor
}

\author{
Son Hee-Jong, Jung Chul-Woo', and Bae Sang-Dae ${ }^{2,+}$ \\ Busan Water Authority, Water Quality Research Institute, Busan, Korea \\ ${ }^{1}$ Ulsan Industry Promotion Techno Park, Ulsan Regional Innovation Agency, Ulsan, Korea \\ ${ }^{2}$ Department of Environmental Engineering, Silla University, Busan, Korea
}

Received August 2008, accepted September 2009

\begin{abstract}
This study examined the special technique of photocatalytic degradation (RPODisk) for removal of taste and odor causing materials, algae, and algal toxin. The RPODisk was effective for removal of these troublesome contaminants. It outperformed the fixed media and the UV irradiation for geosmin removal. The RPODisk performance was comparable to the combination of the UV irradiation with $\mathrm{TiO}_{2}$. The $\mathrm{RPODisk}$ performance was affected by the rotating speed. The faster the speed was, the better the performance. The RPODisk was also effective for removal of algae and algal toxin. The algal activity reduced by $80 \%$ after 30 mins of the treatment. More toxic microcystin (MC)-LR was more difficult to remove than MC-RR. The times for $50 \%$ removal were 23.7 mins for MC-LR and 14.1 mins for MC-RR. Almost 100 mins of the contact time was required to completely remove MC-LR at the rotating speed of $260 \mathrm{rpm}$.
\end{abstract}

Keywords: Photocatalytic degradation, Algae, Algal by-product, Taste and Odour, Rotating disk

\section{Introduction}

Recent industrialization and urbanization resulted in eutrophication of most surface waters in Korea. The typical example is the Nakdong river, which serves as raw water source to southeast region of Korea. Eutrophication was more serious at downstream, where hydration occurred. ${ }^{1)}$ Subsequent algal bloom poses a serious threat to water treatment plants, relying on the Nakdong river. Algal bloom causes several problems including taste and odor ( $\mathrm{T} \& \mathrm{O}$ ), algal toxins, filter clogging. Since conventional treatment is ineffective to handle these problems, advanced processes such as activated carbon and ozonation were introduced to those plants. This study reports the results using the technique rotating photocatalytic oxidation disk reactor (RPODisk).

\section{Materials and Methods}

\subsection{Materials}

Geosmin was selected as the representative $\mathrm{T} \& \mathrm{O}$ causing

\footnotetext{
${ }^{\dagger}$ Corresponding author

E-mail: baesd@silla.ac.kr

Tel: +82-51-999-6270, Fax: +82-51-999-5158
}

material in this study. The standard solution of geosmin $(98 \%$, Sigma-Aldrich, U.S.A.) was diluted in distilled water so that the solution concentration became $10 \mu \mathrm{g} / \mathrm{L}$. Microcystin (MC)-LR and MC-RR were used as the representative algal toxin. The standard solution (Kanto Chemical, Japan) was diluted to $3.9 \mu \mathrm{g} / \mathrm{L}$ (MC-LR) and $2.9 \mu \mathrm{g} / \mathrm{L}$ (MC-RR) in distilled water. Microcystis $\mathrm{sp}$. was collected from the Nakdong river during June to September, 2004 and were used to evaluate the algal activity reduction.

Titanium dioxide powder (Degussa P-25) was used without pretreatment to evaluate the photocatalyitc oxidation performance. When an experiment did not involve the powder form of $\mathrm{TiO}_{2}$, titanium isopropoxide (TTIP; 98\%, JUnsei Chemical Co., Ltd., Japan) was used. TTIP was attached into the fixed media such as the hollow glass bead with $2 \mathrm{~cm}$ of diameter, glass pellet with $2.5 \mathrm{~mm}$ of diameter, and glass disc with $15 \mathrm{~cm}$ of diameter. The germicidal lamp of $10 \mathrm{~W}$ (254 nm, Sankyo Denki, Japan) was used as the ultraviolet (UV) source. Fig. 1 shows the schematic diagram of the RPODisk used in this study.

\section{2. $\mathrm{TiO}_{2}$ Coating}

The glass disc was washed with potassium dichromate before coating. TTIP was mixed with ethyl alcohol and $\mathrm{HCl}$ at the ratio of 10:100:1. The TTIP mixture was then coated into the dried 


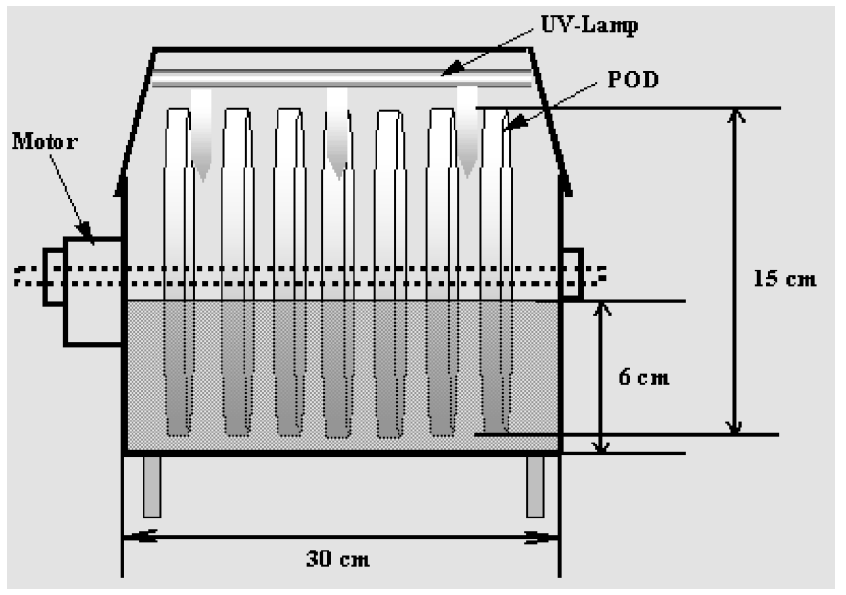

Fig. 1. RPODisk reactor.

glass disc. The titanium coated disc was then heated at $100^{\circ} \mathrm{C}$. The temperature increased at the rate of $10 \sim 20^{\circ} \mathrm{C} / \mathrm{min}$ up to $500^{\circ} \mathrm{C}$, at which it stayed for $4 \mathrm{hrs}$. This process was repeated 20 times before the disc was placed into the reactor. ${ }^{2)}$

\subsection{RPODisk reactor}

The RPODisk used in this study was a batch reactor with a capacity of 3 liter. Two germicidal lamps were placed above the disc. A reflecting glass was put above these lamps so that the UV light heading the reactor roof can be directed into the disc. Seven discs with titanium coating (POD) were connected by a horizontal axis. It was rotated at $24 \sim 260 \mathrm{rpm}$. While POD was rotating, it would contact with water and air, alternatively. Photocatalytic capacity of the titanium oxide would be enhanced through the rotation.

\subsection{Analysis}

Geosmin and 2-MIB were analyzed by GC/MSD with twist pretreatment. For the microcystin analysis, sample of $500 \mathrm{~mL}$ was pretreated using solid phase extraction (Autotrace SPE Workstation, Tekmar, U.S.A.) so that microcystin could be adsorbed onto the sep-pak catridge $\left(\mathrm{C}_{18}\right)$. It was washed and eluted into $20 \%$ methyl alcohol before filtration through $0.2 \mu \mathrm{m}$ membrane filter (Sartorius Minisart RC4, Germany). HPLC was used for the analysis. Table 1 and 2 summarized the analy-

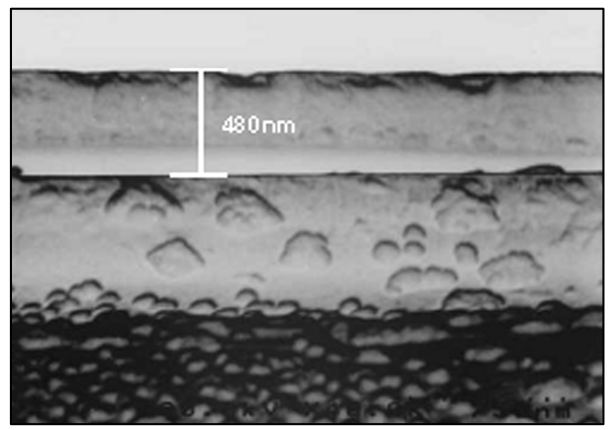

(a)
Table 1. Analytical Conditions of the GC/MSD and the Purge and Trap GC/MSD

- GC : Varian Star 3400 CX

- MSD : Varian Saturn 2000, EI mode

- Column : DB-5MS, $60 \mathrm{~m} \mathrm{ID} \times 0.25 \mathrm{~mm} \times 0.25 \mu \mathrm{m}$

- Oven Temp. : Hold $10 \mathrm{~min}$ at $40^{\circ} \mathrm{C}$

- 1 st step $5^{\circ} \mathrm{C}$ to $150^{\circ} \mathrm{C}$, 2nd step $4^{\circ} \mathrm{C}$ to $250^{\circ} \mathrm{C}$

\section{Purge \& Trap}

- Tekmar LSC-3000 Purge and Trap Concentrator

- Purge Time : $8 \mathrm{~min}$

- Trap : \# J (VOCARB 4000), Desorb $4 \mathrm{~min}\left(260^{\circ} \mathrm{C}\right)$, Bake $5 \mathrm{~min}$ $\left(260^{\circ} \mathrm{C}\right)$

Table 2. Analytical Conditions of the HPLC

- LC: Waters 2690

- UV-Detector : Waters 996, photodiode array detector

- Column : Novac-Pak $\mathrm{C}_{18}, 3.9 \times 150 \mathrm{~mm}$

- Mobile phase : MeOH : $0.05 \mathrm{M}$ phosphate buffer (pH 2.5, 58:42)

- Flow rate : $1 \mathrm{~mL} / \mathrm{min}$

- Detection : $238 \mathrm{~nm}$

tical conditions.

For chlorophyll-a analysis, sample of $500 \mathrm{~mL}$ was first filtered through GF/C filter paper. The paper was then soaked into the $90 \%$ acetone solution of $20 \mathrm{~mL}$. After storing in a dark room at $0^{\circ} \mathrm{C}$ for $12 \mathrm{hrs}$, it was sonicated for $1 \mathrm{~min}$, and put back into the storage for another $12 \mathrm{hrs}$. Centrifuge supernatant was then analyzed UV-absorption at such wavelengths as 750, 664, 647, $630,480 \mathrm{~nm}$ based on the Jeffrey and Humphrey method (CARY 100 conc, Varian, Austrailia). ${ }^{3)}$

For the algal activity measurement, sample was added into the BOD bottle with $1 \mathrm{~mL}$ of $\mathrm{NaH}_{14} \mathrm{CO}_{3}(55.0 \mathrm{mCi} / \mathrm{mmol})$ at the concentration of $10 \mu \mathrm{ci} / \mathrm{mL}$. After being incubated for $3 \mathrm{hrs}$, its radioactive concentration was measured using Liquid Scintillation Analyzer (Packard 2500TR/AB, Canberra, U.S.A.) for algal substrate uptake. ${ }^{4}$

\section{Results and Discussion}

\section{1. $\mathrm{TiO}_{2}$ Coating}

Fig. 2 shows the SEM picture of the POD surface. According to Fig. 2(a), the coating thickness was $480 \mathrm{~nm}$. Fig. 2(b) shows

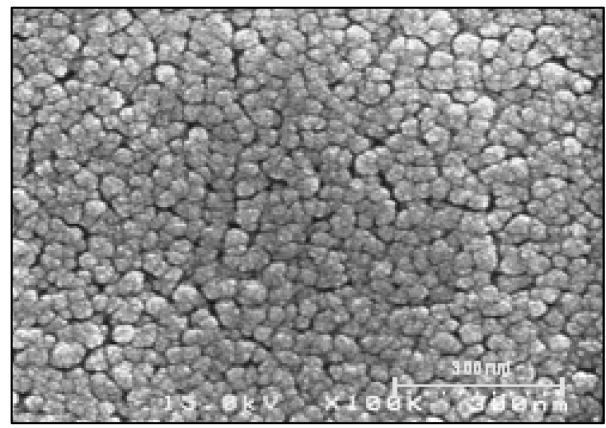

(b)

Fig. 2. SEM photograph of $\mathrm{TiO}_{2}$ immobilized on a glass disk. $[\times 100 \mathrm{k}]$ 
that $\mathrm{TiO}_{2}$ particles packed the glass disc surface.

\section{2. $T \&$ O Removal}

Photocatalytic removal of geosmin was evaluated using powder form of titanium oxide, the titanium fixed media, and the RPODisk. Fig. 3 and Table 3 show the results. The wavelength of $254 \mathrm{~nm}$ was used for the UV irradiation. $\mathrm{TiO}_{2}$ powder was suspended in the solution without pretreatment. The solution was continuously mixed using a magnetic bar so that the powder and the media were kept in suspension. The RPODisk was rotated at $260 \mathrm{rpm}$.

According to Fig. 3, the UV irradiation alone was not effective for the geosmin removal. The fixed media of glass bead and pellet were also ineffective. Their removal efficiencies were less than $10 \%$ even after $1 \mathrm{hr}$ of contact time. The addition of $\mathrm{TiO}_{2}$ improved the removal. The removal efficiency approached $90 \%$ when the UV irradiation was combined with $\mathrm{TiO}_{2}$. The more the $\mathrm{TiO}_{2}$ was dosed, the better the efficiency. It was $87 \%$ at the $\mathrm{TiO}_{2}$ dosage of $50 \mathrm{mg} / \mathrm{L}$ and $96 \%$ at the dosage of $100 \mathrm{mg} / \mathrm{L}$ after $1 \mathrm{hr}$ of contact time. The RPODisk performance was close to the combination of the UV irradiation and $\mathrm{TiO}_{2}$. As the contact time was increased, the removal efficiency improved. The UV irradiation alone removed about $36 \%$ of geosmin after $2 \mathrm{hrs}$. Similar results were obtained with the fixed media. Almost all geosmin were removed after $2 \mathrm{hrs}$ with the RPODisk. The combination of the UV irradiation with $\mathrm{TiO}_{2}$ produced the comparable results to the RPODisk only when the $\mathrm{TiO}_{2}$ dosage was $100 \mathrm{mg} / \mathrm{L}$. The RPODisk performed better than the fixed media in the geosmin removal. The fixed media was dispersed unevenly. Some settled, and others floated. Because of the uneven distribu-

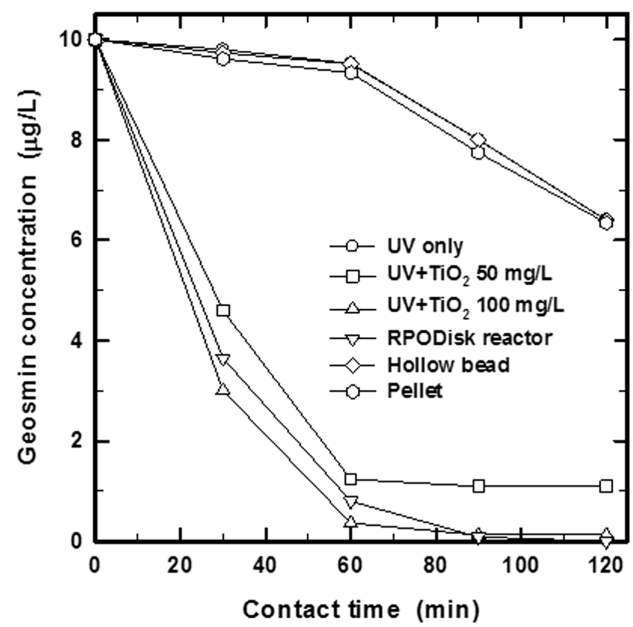

Fig. 3. Photocatalytic degradation of geosmin under different conditions tion, the photocatalytic reaction failed to occur all over the solution. However, the RPODisk promoted the photocatalytic reaction both in air and water, which resulted in the better removal efficiency. The RPODisk could be more beneficial than the combination of the UV irradiation with $\mathrm{TiO}_{2}$ for application to water treatment plant because the $\mathrm{UV}-\mathrm{TiO}_{2}$ combination process needs one more step to separate the $\mathrm{TiO}_{2}$ particle. After the photocatalytic reaction, the $\mathrm{TiO}_{2}$ particles should be separated from water by filtration. On the other hand, the RPODisk does not need an additional step.

Fig. 4 shows the effect of the rotating speed of the RPODisk on the removal of gesomin and 2-MIB. While the The rotating speed varied to 24,80 , and $260 \mathrm{rpm}$, the removal of geosmin and 2-MIB were monitored. According to Fig. 4, the best performance was obtained at the highest speed $(260 \mathrm{rpm})$. The fast rotating possible reduced the boundary layer thickness, which encourage the better contact between the POD and the contaminants. The removal efficiency was different with the contaminant type. Geosmin was more difficult to remove than 2-MIB. The time needed for 90 removal was 105 mins for geosmin and 83 mins for 2-MIB at $24 \mathrm{rpm}$. It was 58 and $52 \mathrm{mins}$ at $260 \mathrm{rpm}$.

\subsection{Removal of Algae and Algal Toxin}

The use of the RPODisk was extended for removal of algae. It was rotated at $260 \mathrm{rpm}$. Microcystis sp. was directly added into raw water. Fig. 5 shows the results. According to Fig. 5, the algal activity reduced rapidly. The reduction was complete after 30 mins. The chlorophyll-a concentration was slower than the algal activity. It slowly decreased. The $83 \%$ reduction was obtained after 4 hrs.

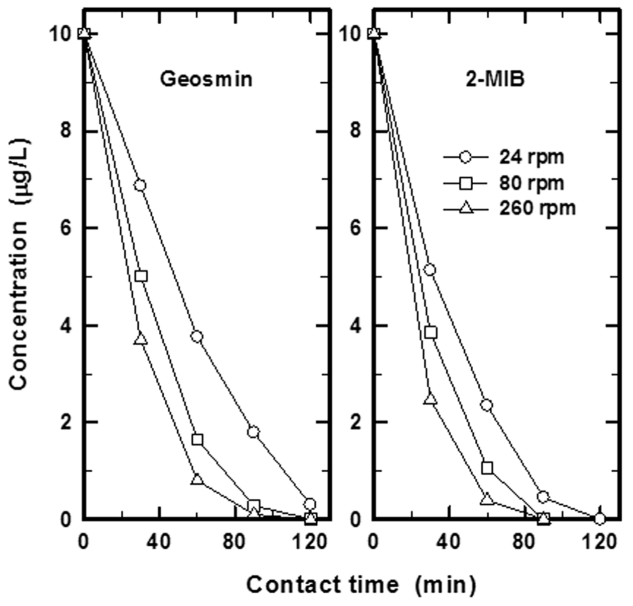

Fig. 4. Effect of the rotating speed of the RPODisk on the removal of geosmin and 2-MIB.

Table 3. Summary of Removal efficiency of geosmin under different conditions

\begin{tabular}{cc|ccccc}
\hline Item & UV only & $\begin{array}{c}\mathrm{TiO}_{2} \text { powder } \\
50 \mathrm{mg} / \mathrm{L}\end{array}$ & $\begin{array}{c}\mathrm{TiO}_{2} \text { powder } \\
100 \mathrm{mg} / \mathrm{L}\end{array}$ & RPODisk & Hollow Bead & Pellet \\
\hline $60 \mathrm{~min}$. & $<4.8 \%$ & $>87.0 \%$ & $>96.0 \%$ & $>92.0 \%$ & $<5.0 \%$ & $<6.7 \%$ \\
\hline $120 \mathrm{~min}$. & $<36.0 \%$ & $>89.0 \%$ & $>98.0 \%$ & $>99.0 \%$ & $<36.1 \%$ & $<37.0 \%$ \\
\hline
\end{tabular}




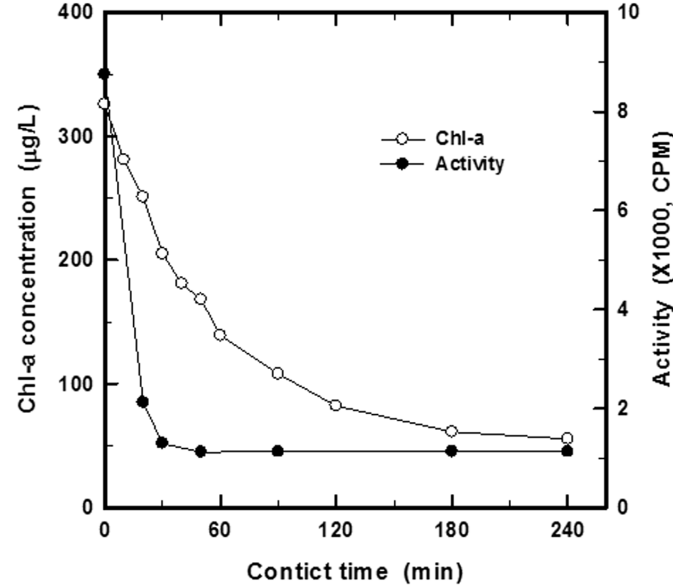

Fig. 5. Variation of Chlorophyll-a and algae-activation in the RPOD reaction.
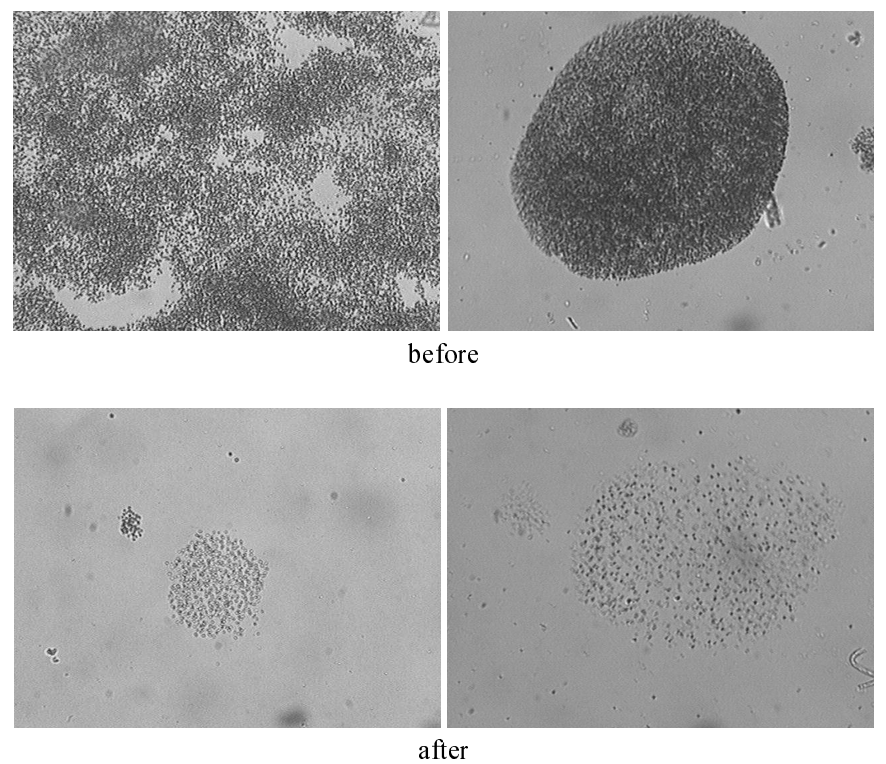

Fig. 7. Photograph of Microcystis sp. before and after photodegradation by the RPODisk reactor.

Fig. 6 shows the results of algal toxin removal. According to Fig. 6, more toxic MC-LR was more difficult to remove than MC-RR. MC-RR was almost completely removed after 90 mins of contact time, but MC-LR required 120 mins. The time required to remove $50 \%$ of these algal toxin was 14.1 mins for MC-RR and 23.7 mins for MC-LR. Fig. 7 shows the pictures of Microcystis sp. It formed colony originally. However, after 90 mins of contact time, the colony was completely dispersed.

\section{Conclusions}

The RPODisk removed geosmin effectively. It outperformed

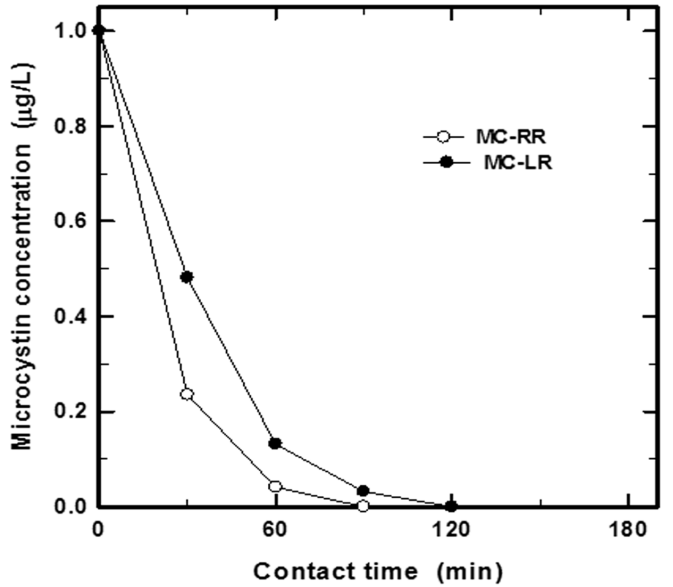

Fig. 6. Variation of microcystin-RR and -LR removal in the RPOD reaction.

the fixed media and the UV irradiation. The RPODisk performance was comparable to the combination of the UV irradiation with $\mathrm{TiO}_{2}$. The RPODisk performance was affected by the rotating speed. The faster the speed was, the better the performance. The speed of $260 \mathrm{rpm}$ gave the best results in this study. The RPODisk was also effective for removal of algae and algal toxin. The algal activity reduced by $80 \%$ after 30 mins of the treatment. The chlorophyll-a concentration was slower than the algal activity. It took $4 \mathrm{hrs}$ to reduce the chlorophyll-a concentration by $83 \%$. More toxic MC-LR was more difficult to remove than MC-RR. The times for $50 \%$ removal were 23.7 mins for MC-LR and $14.1 \mathrm{mins}$ for MC-RR. Almost 100 mins of the contact time was required to completely remove MC-LR at the rotating speed of $260 \mathrm{rpm}$.

\section{References}

1. Kim, W. H., Choi, A. R., and Lee, J. A., "The occurrence of microcystins in the Nakdong river," Korean J. Algae, 14(4), 237-246. (1999).

2. Son, H. J., Jung, C. W., and Kim, S. H., "Photocatalytic degradation of bisphenol-A using a rotating photoctalyticoxidation drum reactor (RPODR), Environ. Eng. Res., 13(4), 197-202 (2008).

3. Jeffrey, S. W. and Humphrey, G. F., "New Spectrophotometric equations for determining chlorophyll a, b, c1 and c2 in higher plants, algae and natural phytoplankton," $J$. of Biochem. physiol. pflanzen., 167, 191-194 (1975).

4. Bell, R. T., Ahlgren, G. M., and Ahlgren, I., "Estimating bacterioplankton production by the $[3 \mathrm{H}]$ thymidine incorporation in a eutrophic Swedish Lake," Appl. Environ. Microbiol., 45, 1709-1721 (1983). 